Cómo citar este trabajo: González-Leonardo, M., \& López Gay, A. (2019). Emigración y fuga de talento en Castilla y León. Boletín de la Asociación de Geógrafos Españoles, 80, 2612, 1-31. http://dx.doi.org/10.21138/bage.2612

\title{
Emigración y fuga de talento en Castilla y León
}

\author{
Out-migration and brain drain in Castile and León
}

\author{
Miguel González-Leonardo \\ mgonzalez@ced.uab.es \\ Antonio López-Gay \\ tlopez@ced.uab.es \\ Centre d'Estudis Demogràfics \\ Universitat Autònoma de Barcelona (España)
}

\section{Resumen}

Castilla y León es la comunidad autónoma de la que más jóvenes han salido, en términos relativos, hacia otras regiones del territorio español, con un balance especialmente deficitario entre la población con estudios universitarios. El elevado nivel de instrucción de la población local y un mercado de trabajo donde escasean los empleos cualificados, se traducen en la fuga del talento allende los límites regionales. A partir de los microdatos del Censo de 2011, estudiamos la posición de Castilla y León como región exportadora de personas con estudios superiores en el contexto nacional, el balance con otras comunidades autónomas, el grado de sobrecualificación en origen y destino y, mediante la aplicación de un modelo de regresión logística, los factores sociodemográficos que explican la emigración.

Palabras clave: emigración; fuga de talento; Castilla y León; sobrecualificación; factores duros.

\begin{abstract}
Castile and León hold among all the regions the highest proportion of young adults living in other areas of Spain. The negative balance is higher in the case of people with university studies. The high level of education of the native population and a labor market where the qualified jobs scarce, are the main reasons explaining the region's brain drain. We use the microdata from the 2011 Census
\end{abstract}


to analyze the status of Castile and León as a region exporting highly educated population to other areas in Spain, the migratory relation with other Autonomous Communities and the degree of overqualification in origin and in destination. In addition, we use a logistic regression model to capture the sociodemographic factors explaining internal migration.

Key words: internal migration; brain drain; Castile and León; overqualification; hard factors.

\section{Introducción}

La población de la región castellana y leonesa se caracteriza por tener un nivel de instrucción elevado en comparación con el conjunto nacional. Tradicionalmente, la incidencia del analfabetismo se ha situado por debajo de la media española (Pérez Díaz, 1971; 1972). En la actualidad, Castilla y León es una de las comunidades autónomas (CC. AA.) con la proporción de universitarios más elevada. Según los datos del Censo de 2011, el 36,2 \% de los jóvenes autóctonos de 25 a 39 años estaba en posesión de un título universitario (España: 32,2 \%). En el año 2015, Castilla y León obtiene los mejores resultados académicos de toda España en el Informe PISA (Programme for International Student Assessment) y en el contexto internacional su rendimiento se sitúa en línea con algunos de los primeros países, como Singapur, Japón, Canadá, Finlandia o Corea del Sur (Junta de Castilla y León, 2016).

A parte de registrar un nivel educativo elevado entre la población local, se trata de un territorio con una marcada tendencia emigratoria. Es la comunidad autónoma (C. A.) que más jóvenes autóctonos tiene viviendo en otras partes del territorio español, un 24,7\%, frente al 13,1\% de la media nacional. El tejido productivo regional tiene un importante déficit de actividades tecnológicas e innovadoras, con el consiguiente desajuste entre el nivel de cualificación de su población y la estructura ocupacional del mercado de trabajo. Sin embargo, esta circunstancia no es exclusiva de Castilla y León. La sobrecualificación se da, en mayor o menor medida, en toda España, pero tiene mayor incidencia, como es lógico, en las CC. AA. menos dinámicas. En las áreas más desarrolladas, principalmente en las aglomeraciones urbanas de las dos ciudades globales, Madrid y Barcelona, hay una mayor concentración de actividades punteras y puestos de trabajo cualificados.

Este contexto plantea una serie de interrogantes, que serán las preguntas de investigación de las que parte el presente artículo: ¿cuál es la situación de Castilla y León como región emigratoria de talento en el contexto nacional?, ¿es la comunidad autónoma que más jóvenes en posesión de un título universitario tiene viviendo en otras partes de España?, ¿qué proporción de personas con estudios superiores hay en el colectivo emigrado?, ¿la población que abandona la comunidad tiene un nivel de instrucción superior a la que llega desde otras partes de España?, ¿con qué regiones se producen estos intercambios?, ¿existe un grado de sobrecualificación mayor entre los jóvenes 
autóctonos que se han quedado en Castilla y León respecto a los que se han marchado?, ¿qué factores sociodemográficos influyen en la probabilidad de emigrar? Las hipótesis iniciales apuntan a que se trataría de la región con el colectivo emigrado más formado, que las principales áreas receptoras del talento regional serían las provincias de Madrid y Barcelona y que la sobrecualificación será más elevada entre los castellanos y leoneses sedentarios respecto a los emigrados. Para conocer la incidencia de algunos factores individuales en la emigración, se aplicará un modelo de regresión logística. Según lo observado en el análisis descriptivo, se prevé que el sexo, el nivel de instrucción, el perfil ocupacional y el lugar de nacimiento tengan un poder explicativo destacado.

\section{Los movimientos migratorios en España y la circulación de talento}

En líneas generales, España ha seguido una trayectoria migratoria similar a los países europeos de industrialización tardía, como Italia o Portugal (García Barbancho, 1967). Dentro del contexto nacional, Castilla y León se caracteriza por ser una región claramente emigratoria, con una dinámica parecida a otras áreas españolas que poseen características análogas (Castilla-La Mancha, Extremadura...). Sin contar los movimientos migratorios preindustriales (Reher, 1990; Silvestre, 2002), a partir de 1860 se puede hablar de una salida continuada e intensa de población rural hacia América y algunos enclaves urbanos e industriales españoles, que se intensifica en las tres primeras décadas del siglo XX (Erdozáin y Mikelarena, 1996; Silvestre, 2002). Durante esta época, el abundante saldo natural logró frenar las pérdidas ocasionadas por el balance migratorio negativo (García Zarza, 1983; Caballero, Delgado \& Martínez, 2012). Con el estallido de la crisis de 1929, que llega a España con cierto retraso, la Guerra Civil y la posterior etapa de autarquía, la intensidad emigratoria se reduce (García Barbancho, 1967; Vidal, 1979; Silvestre, 2002; Franch, 2009). Entre 1955 y 1973, la etapa desarrollista de la economía española, se produce el "vaciamiento demográfico de Castilla y León" (Caballero, Delgado \& Martínez, 2012). Los movimientos migratorios alcanzaron una envergadura sin precedentes y modificaron por completo la distribución territorial de la población. Se produjo un fuerte éxodo rural que supuso la despoblación de la mayor parte del interior peninsular y la concentración de habitantes en sectores determinados (Cabré, Moreno \& Pujadas, 1985). Ni siquiera el elevado balance natural del baby boom logró compensar el éxodo masivo de población (García Zarza, 1983; Caballero, Delgado \& Martínez, 2012). La emigración también trajo consigo unas consecuencias desastrosas sobre la nupcialidad emigración diferencial por sexos- y los nacimientos (Del Rey y Cebrián, 2009).

Entre 1975 y finales de los 90, los flujos migratorios pierden intensidad y se difuminan las direcciones interprovinciales (Cabré, Moreno \& Pujadas, 1985; García Barbancho y Delgado Cabeza, 1988; Olano, 1990; García Coll \& Puyol, 1997; Recaño, 2004b, 2006; Ródenas, 1994), con un peso relativamente destacado de las migraciones de retorno (Pascual de Sans, 
1983; Recaño, 2004a, 2004b, 2006). El País Vasco deja de ser un polo de atracción para convertirse en expulsor, mientras que Barcelona y Madrid registran saldos negativos en años concretos. En Castilla y León, las corrientes de retorno son más reducidas que en otras regiones de tradición emigratoria y no compensan la salida continuada de efectivos (Recaño, 2004a), a pesar de que se produjo un flujo de retorno destacable desde el País Vasco, no tanto desde Madrid u otras áreas receptoras (Rapado, 1985). Pese a la baja movilidad de trabajadores durante este periodo, hay oscilaciones en la intensidad migratoria asociadas a la coyuntura económica, aumentando en las etapas de expansión y reduciéndose en las fases recesivas (Recaño \& Cabré, 2003).

Durante los últimos años del siglo XX y los primeros del siglo XXI se producen varios hitos que modifican el sistema migratorio español: la llegada masiva de inmigración extranjera (Reher \& Requena, 2011; Arango, 2015; Domingo \& Cabré, 2015; López de la Hera, 2015; Galeano, 2016; Recaño, 2016); el incremento de las migraciones intraprovinciales, principalmente por los procesos de suburbanización (Feria \& Susino, 2006; Módenes, 2006; López-Gay, 2008); y el aumento de los desplazamientos interregionales de la población autóctona (Cámara, 2009). Como resultado, se produce un notable aumento de la movilidad y las CC. AA. tradicionalmente emisoras, como Castilla y León, se convierten en receptoras de personas procedentes del extranjero (Delgado \& Martínez, 2016a, 2016b), a pesar de que las bajas de población local aumentan. A partir de 2008, con el periodo económico recesivo, la afluencia de extranjeros se reduce, aunque en los primeros años las pérdidas no son tan acusadas por la reagrupación familiar (Domingo \& Sabater, 2013; Domingo \& Blanes, 2015). Este fenómeno se produce con cierto retraso en las CC. AA. de menos crecimiento demográfico (Delgado \& Martínez, 2016a). La movilidad residencial también cae, ahora son las cohortes vacías las demandantes de vivienda (Módenes \& López Colás, 2014; López-Gay, 2016). No obstante, los desplazamientos de media y larga distancia de la población autóctona joven continúan incrementándose, tanto las salidas hacia el exterior (González Ferrer, 2013; Herrera Ceballos, 2014; Rubio Castillo, 2014; Artal, Navarro \& Requena, 2015) como los movimientos interiores entre regiones menos dinámicas y áreas más productivas, descrito para el caso gallego (González Laxe, Martín Bermúdez \& Martín Palmero, 2013) y en Castilla y León (González-Leonardo, 2017; González-Leonardo \& López-Gay, 2019).

Recaño (2014) pone de manifiesto que las regiones del interior son las que presentan las tasas migratorias netas negativas más intensas, sobre todo las cercanas a la capital, entre las que se incluye el territorio castellano y leonés, y obtiene una mayor probabilidad de ser un emigrado interregional con nacionalidad española en el Censo de 2011 que en el de 2001. También refleja que Castilla y León es la región española con el coeficiente emigratorio más alto y que la educación es determinante a la hora de efectuar un movimiento migratorio: a mayor nivel de instrucción, la probabilidad de emigrar se incrementa. González Laxe, Martín Bermúdez y Martín Palmero (2013) 
perciben un aumento en los flujos de salida desde Galicia hacia otras partes de España y denominan este nuevo estadio como "la tercera etapa emigratoria".

Sobre los movimientos de trabajadores cualificados, son relevantes algunas aportaciones que constatan la salida de españoles con estudios superiores hacia los países de Europa Noroccidental durante la crisis económica (González Ferrer, 2013; Herrera Ceballos, 2014; Rubio Castillo, 2014), o canalizados en dirección al continente americano (Mendoza \& Ortiz Guitart, 2006). En referencia a las migraciones interiores, Cabrer, Serrano y Simarro (2009) recogen un aumento de las tasas brutas entre los individuos con nivel de instrucción de segundo y tercer grado para el periodo 1991-2005, y González Laxe, Martín Bermúdez y Martín Palmero (2013) para la región gallega.

Las migraciones de trabajadores cualificados han sido ampliamente desarrollados en la literatura internacional a partir de dos marcos teóricos (Meyer \& Brown, 1999; Saxenian, 1999; Brown, 2000; Beine, Docquier \& Rapoport, 2008; Sleutjes \& Roterman, 2014): el brain drain, que sitúa a los ámbitos receptores como beneficiarios y a los emisores como perdedores de capital humano y de la consiguiente inversión realizada en educación; y la teoría del brain gain, que no considera los recursos humanos cualificados emigrados como una pérdida neta y definitiva, sino como un patrimonio potencial a ser explotado por la región emisora. Esta última perspectiva asume que los profesionales emigrados son recursos empleados en mejores condiciones que las ofertadas en origen; como resultado, si la región natural logra utilizar en su favor estos recursos, mediante el retorno de estas personas o la circulación del conocimiento, habrá logrado una enorme capitalización (Meyer \& Brown, 1999; Gordon, 2007). También se han constatado evidencias de situaciones de brain waste (desperdicio de cerebros) cuando el talento retorna y es infrautilizado (Galliard, 1991). Por otra parte, se pueden encontrar numerosos estudios de caso: trabajadores indios altamente cualificados emigrados a Gran Bretaña (Oommen, 1989), fuga de cerebros desde Latinoamérica hacia Estados Unidos (Albornoz, Fernández Polcuch y Alfaraz, 2002), inmigrantes posgraduados procedentes de la UE en Manchester - que se desplazan con expectativa de cumplir sus proyectos profesionales- (Kennedy, 2010) o desde países pertenecientes a la extinta Unión Soviética hacia Europa Noroccidental (Rirk, 2018)... Pethe y Hafner (2013) registran un aumento reciente de la movilidad entre los profesionales cualificados en el área metropolitana de Amsterdam, y añaden que la internacionalización de las empresas y de la educación, las redes sociales y la libre circulación de ciudadanos comunitarios dentro de las fronteras de la UE son algunos de los factores en los que podría tener su génesis este proceso.

En referencia a los destinos elegidos por los emigrados altamente cualificados, los principales focos de atracción son las ciudades globales. Según la teoría del sistema mundial (Wallerstein, 1974; Portes \& Walton, 1981; Saseen, 1993), estas ciudades concentran las actividades tecnológicas, financieras y los servicios avanzados, condiciones que fomentan la afluencia de inmigrantes, 
principalmente de población con un grado de instrucción elevado (Sassen, 1993). En la elección del destino entran en juego lo que algunos autores denominan como hard factors (factores duros) empleo, salario, redes personales, accesibilidad- y soft factors (factores blandos) -ocio y cultura, comodidades, ambiente- (Florida, 2002; Sleutjes \& Roterman, 2014). Florida (2002) centra el foco de atención en las condiciones blandas como determinantes en la elección de destino por parte de la "clase creativa", mientras que los factores duros suelen ser más relevantes en la mayor parte de los estudios realizados (Brown \& Meczynski, 2009; Martin-Brelot et al., 2010; Miguélez \& Moreno, 2014), con un protagonismo destacado del empleo (Hansen \& Niedomysl, 2009; Buch et. al, 2014) y las redes personales (Musterd \& Murie, 2010). Hansen and Niedomysl (2009) manifiestan que las condiciones blandas son complementarias a los factores duros. En los movimientos migratorios y su dirección están presentes diversos factores de atracción-repulsión (pullpush) (Lee, 1966; Arango, 1985; Sassen, 1993; Pugliese, 1997) y la distancia juega un papel determinante, no solo desde un punto de vista físico, sino también desde una connotación más amplia (Zipf, 1946; Arango, 1985).

El mercado laboral español se caracteriza por tener un elevado grado de sobrecualificación, especialmente entre la población joven, con niveles ampliamente superiores en comparación a otros países de la OCDE (Dolado, Felgueroso \& Jimeno, 2000; Quintini 2011; IVIE, 2012). Se considera que un trabajador está sobrecualificado cuando posee más competencias de las necesarias para realizar su ocupación: formación, experiencia y actitudes, principalmente (Serracant, 2005). En los estudios que versan sobre la materia se suele tomar como referencia el desajuste entre el nivel educativo y los requerimientos del puesto de trabajo (Madrigal, 2003; Gobernado, 2007), pues otro tipo de competencias son más difíciles de cuantificar. El debate en torno a la sobrecualificación surge en los años 70 en Estados Unidos, tras la expansión de la educación superior en la segunda mitad del siglo XX (Berg, 1970; Freeman, 1976). En España, este fenómeno se produce, principalmente, desde los 70, mientras que el cambio en el modelo productivo y los requerimientos de los puestos de trabajo no parecen ir al mismo ritmo, con la consiguiente dificultad de los jóvenes para incorporarse al mercado de trabajo en un puesto acorde a su cualificación (Serracant, 2005; García Montalvo, 2009).

A nivel individual, no rentabilizar el esfuerzo realizado en la adquisición de conocimientos provoca insatisfacción, cierta frustración y, por consiguiente, una menor productividad (Serracant, 2005; Sánchez-Sellero et. al, 2013), que se suman a la infrautilización de conocimientos y a la pérdida de la inversión realizada en educación (Serracant, 2005). Sánchez Sellero et al. (2013) constatan un aumento de la sobrecualificación durante el periodo de crisis económica: ha disminuido la oferta de empleo y han empeorado las condiciones laborales y, ante la escasez de salidas profesionales, los jóvenes deciden seguir estudiando, lo que aumenta la proporción de personas instruidas. En Castilla y León, al registrarse un nivel educativo por encima de la media nacional y haber un tejido 
productivo más precario, la sobrecualificación se ve acrecentada. En ocasiones, la sobrecualificación se explica por la resistencia a la movilidad geográfica: algunas personas deciden no emigrar de su lugar de residencia y aceptar un empleo de menor cualificación con tal de no alejarse de su círculo familiar o social (IVIE, 2009; Sánchez Sellero et. al, 2013).

\section{Fuentes y método}

Se ha utilizado una metodología de tipo cuantitativo, aplicada a los microdatos del Censo de Población del año 2011 (Instituto Nacional de Estadística). A partir de esta fuente tipo stock, se ha seleccionado a la población de 25 a 39 años, el rango etario que presenta una mayor intensidad emigratoria, utilizando las variables: región de nacimiento, C. A. de residencia, nivel de instrucción y ocupación. Obviamente, al trabajar con el Censo, no se incluye a los autóctonos que viven fuera de España -habría que recurrir al Padrón de Españoles Residentes en el Extranjero, que no proporciona información detallada-. Se han excluido del análisis, por tamaño de la muestra, las ciudades autónomas de Ceuta y Melilla. La aplicación de la variable año de llegada a la C. A. permitiría excluir del análisis a la población que se ha formado en destino. No obstante, entendemos que la fuga de talento no se refiere únicamente al lugar donde se obtiene el título universitario, sino que la pérdida de capital humano y de las cualidades potenciales del individuo en origen también son relevantes, por lo que analizaremos el total del colectivo emigrado.

En el apartado cuatro, con la finalidad de contextualizar la situación de Castilla y León a escala nacional, se ha filtrado a la población autóctona de cada comunidad autónoma en el rango etario citado, y se ha seleccionado el stock de personas que residen en una región distinta a la de nacimiento, y el de emigrados que poseen estudios de tercer grado. A continuación, se obtiene la proporción de personas con estudios universitarios respecto al total de individuos nacidos en la región y también de la población emigrada.

En adelante, se centra el foco de atención únicamente en Castilla y León. En el quinto epígrafe se cuantifica el volumen total de población castellana y leonesa que vive en otras regiones españolas, las personas nacidas en otras CC. AA. que viven en Castilla y León y se hace un balance entre ambos colectivos, por nivel educativo - con estudios universitarios e individuos sin estudios superiores-. De esta forma, se puede medir el nivel de instrucción de las personas que entran y de las que salen. Seguidamente, se analiza el balance de población, también por nivel de cualificación, entre Castilla y León y las distintas regiones españolas; y se utilizan los sistemas de información geográfica para cartografiar los destinos del colectivo autóctono emigrado, pero esta vez por provincia de destino.

En el sexto apartado se analiza la variable censal ocupación, que hace referencia a la Clasificación Nacional de Ocupaciones (CNO) a un dígito, y se observa el perfil profesional de los jóvenes 
autóctonos castellanos y leoneses con estudios universitarios, tanto de la población residente en Castilla y León como del colectivo emigrado. De esta forma, podemos comparar el grado de sobrecualificación en origen y destino. La clasificación original del INE establece diez categorías, aunque en este caso son ocho: se ha agrupado a los trabajadores industriales y de construcción junto a los empleados cualificados del sector primario en una única categoría, y se han eliminado las ocupaciones militares por su escasa relevancia en la muestra. La nueva clasificación queda de la siguiente manera: "servicios personales", "ocupaciones elementales", "trabajadores de la industria, la construcción y el sector primario", "montadores de maquinaria", "contables y administrativos", "profesionales y técnicos de apoyo", "técnicos y profesionales científicos e intelectuales", "directivos y gerentes".

Finalmente, con el objetivo de medir el riesgo de emigrar que tienen los castellanos y leoneses en función de distintas características sociodemográficas, se ha realizado un modelo de regresión logística binaria aplicado a los microdatos del Censo de 2011. Las personas autóctonas de Castilla y León, que tienen entre 25 y 39 años y residen en el territorio nacional compondrían la población riesgo, dividida en dos categorías: sedentarios y emigrantes. Las variables sociodemográficas incluidas en el modelo y recodificadas a partir de las preguntas censales han sido:

I. Sexo.

II. Edad: 25-29, 30-34, 35-39.

III. Nivel de instrucción: primaria o inferior, EGB-ESO-FP1, bachillerato-FP2, universidad.

IV. Ámbito territorial de nacimiento: municipios menores de $<2000$ habitantes, de 2001 a 5000, 5001-10000, no capitales >10000 hab. y capitales de provincia (Al ser una variable autodeclarada, puede no coincidir el municipio de nacimiento con el de residencia de la madre en el momento del parto o el de inscripción. Se estima que las capitales provinciales y los municipios de mayor tamaño tienen un peso sobredimensionado).

V. Provincia de nacimiento: las nueve provincias que componen Castilla y León.

VI. Tipo de empleo: se establecen las ocho categorías CNO a un dígito, definidas anteriormente.

VII. Situación profesional: trabajadores por cuenta ajena, empresario-autónomos y otras situaciones.

Los modelos de regresión se utilizan para conocer la incidencia de variables explicativas sobre una variable explicada. La regresión logística binaria se aplica cuando hay una variable dependiente dicotómica, "sí y no" (sedentario y emigrante), y se quiere conocer la probabilidad del "sí" en 
función de distintas variables explicativas categóricas. En el caso que nos atañe, el riesgo de emigrar respecto a un grupo de referencia, a partir de las categorías establecidas en cada una de las variables independientes. Si los coeficientes obtenidos, llamados Exp(B) u Odds ratio, superan el valor 1, los individuos de la categoría en cuestión tienen una probabilidad mayor de emigrar que los del grupo de referencia. Si es inferior, tienen un riesgo más reducido. El $R^{2}$ representa el poder explicativo del modelo. La regresión logística se puede expresar de la siguiente manera:

$$
\log \left(P_{i} /\left(1-P_{i}\right)\right)=\beta_{0}+\beta_{1} x_{1}+\beta_{2} x_{2}+\beta_{3} x_{3}+\ldots+\beta_{n} x_{n}
$$

$\mathrm{P}_{\mathrm{i}}$ : proporción de los casos "sí". 1-P: proporción de los casos "no". $\mathrm{x}$ : variable independiente. $\beta$ : coeficiente asociado a la variable independiente

\section{Castilla y León: La fábrica de talento de España}

Según los datos del Censo de 2011, en el conjunto de España había 1175675 personas autóctonas entre 25 y 39 años que residían en una C. A. distinta a la de nacimiento, el 13,1 \% de la población nacional perteneciente a este rango etario (Tabla 1). Solo unas pocas regiones se sitúan por debajo de esta proporción: Canarias, la Comunidad Valenciana, Andalucía, Murcia, Baleares, Cataluña y Galicia. El resto de CC. AA. tenían porcentajes más elevados: Navarra, Cantabria, Madrid, Asturias, Aragón, La Rioja, País Vasco, Castilla-La Mancha, Extremadura y Castilla y León. El colectivo emigrado en esta última es especialmente llamativo, con uno de cada cuatro jóvenes viviendo en otra autonomía. En números absolutos, a pesar del escaso volumen de personas jóvenes nacidas en Castilla y León, ocupa la cuarta posición, con 126615 emigrados, detrás de Madrid, Cataluña y Andalucía, CC. AA. que tienen un volumen de población mucho mayor y una estructura etaria menos envejecida.

En cuanto a la población con estudios de tercer grado, la proporción de emigrados se eleva en todas las regiones, a excepción de Madrid y Cataluña (en País Vasco es ligeramente superior). Las personas con un nivel de instrucción elevado también presentan una mayor movilidad en otros estudios sobre migraciones que incluyen la variable educativa (Cabrer, Serrano \& Simarro, 2009; González Laxe, Martín Bermúdez \& Martín Palmero, 2013; Recaño, 2014). La media nacional que establece el Censo es del 16,5\%, 477960 personas de 25 a 39 años y con estudios universitarios que residían en una CC.AA. diferente a la de nacimiento. Nuevamente, Castilla y León ocupa la primera posición en el ranking, con un 35,5\%, y en números absolutos asciende hasta la segunda, sumando 65990 efectivos -Madrid es la primera (67 760)-. Detrás se sitúan regiones que, al igual que Castilla y León, se caracterizan por ser expulsoras de población y, en algunos casos, por tener una estructura productiva limitada: Castilla-La Mancha, La Rioja, Extremadura, Cantabria, Asturias, Aragón, País Vasco, Navarra. Las CC. AA. que menos expulsan a sus jóvenes cualificados son Cataluña, Canarias y la Comunidad Valenciana, con proporciones de emigrados 
de 9,6, 9,6 y 10,9\%, respectivamente. También registran porcentajes reducidos Andalucía, Baleares, Madrid, Murcia y Galicia.

Tabla 1. Emigrados y emigrados con estudios universitarios entre 25 y 39 años, por C. A. de nacimiento (2011)

\begin{tabular}{|c|c|c|c|c|}
\hline C. A. & Emigrados & $\begin{array}{l}\% \text { sobre los } \\
\text { nacidos en la } \\
\text { región }\end{array}$ & $\begin{array}{l}\text { Emigrados } \\
\text { con estudios } \\
\text { universitarios }\end{array}$ & $\begin{array}{l}\% \text { sobre los } \\
\text { universitarios } \\
\text { nacidos en la } \\
\text { región }\end{array}$ \\
\hline Castilla y León & 126615 & $24,7 \%$ & 65990 & $35,5 \%$ \\
\hline Castilla-La Mancha & 81080 & $22,0 \%$ & 34570 & $31,8 \%$ \\
\hline La Rioja & 10995 & $20,4 \%$ & 5640 & $30,2 \%$ \\
\hline Extremadura & 52420 & $22,2 \%$ & 20590 & $30,1 \%$ \\
\hline Cantabria & 19550 & $16,4 \%$ & 9430 & $26,7 \%$ \\
\hline Asturias & 38860 & $17,2 \%$ & 19170 & $24,9 \%$ \\
\hline Aragón & 41470 & $17,4 \%$ & 21380 & $24,0 \%$ \\
\hline País Vasco & 101245 & $20,7 \%$ & 41700 & $21,8 \%$ \\
\hline Navarra & 16955 & $15,1 \%$ & 8405 & $19,3 \%$ \\
\hline Galicia & 64600 & $11,3 \%$ & 25260 & $15,3 \%$ \\
\hline Murcia & 26790 & $9,8 \%$ & 11340 & $15,2 \%$ \\
\hline C. de Madrid & 199370 & $17,0 \%$ & 67760 & $14,5 \%$ \\
\hline Baleares & 17250 & $10,4 \%$ & 6245 & $12,8 \%$ \\
\hline Andalucía & 149965 & $8,6 \%$ & 55885 & $11,8 \%$ \\
\hline C. Valenciana & 67095 & $7,6 \%$ & 30440 & $10,9 \%$ \\
\hline Cataluña & 142445 & $10,2 \%$ & 45180 & $9,6 \%$ \\
\hline Canarias & 18970 & $4,8 \%$ & 8975 & $9,6 \%$ \\
\hline Total nacional & 1175675 & $13,1 \%$ & 477960 & $16,5 \%$ \\
\hline
\end{tabular}

Fuente: elaboración propia a partir del Censo de 2011 (INE, 2011)

En referencia a la estructura educativa regional, teniendo en cuenta el total de autóctonos entre 25 y 39 años con estudios universitarios (emigrados y residentes en la propia región), existen diferencias bastante marcadas según la comunidad autónoma de nacimiento (Tabla 2). Castilla y León presenta 
un perfil educativo más instruido que el conjunto nacional $(36,2 \%)$, cuatro puntos porcentuales por encima de la media, aunque en el ranking de población con estudios universitarios se sitúa en quinta posición, por detrás de Madrid, País Vasco, Navarra y Aragón, que encabezan la lista. Los porcentajes más reducidos se dan entre los autóctonos de Canarias, Andalucía, Murcia y Galicia.

Tabla 2. Población entre 25 y 39 años con estudios universitarios, por C. A. de nacimiento, total y emigrados, 2011

\begin{tabular}{|c|c|c|c|c|}
\hline C. A. & $\begin{array}{c}\text { Todos los } \\
\text { nacidos en la } \\
\text { C. A. }\end{array}$ & $\begin{array}{l}\text { \% sobre la } \\
\text { población } \\
\text { nativa }\end{array}$ & Emigrados & $\begin{array}{c}\text { \% sobre los } \\
\text { emigrados }\end{array}$ \\
\hline Castilla y León & 186070 & $36,2 \%$ & 65990 & $52,1 \%$ \\
\hline Aragón & 89170 & $37,5 \%$ & 21380 & $51,6 \%$ \\
\hline La Rioja & 18680 & $34,7 \%$ & 5640 & $51,3 \%$ \\
\hline Navarra & 43455 & $38,7 \%$ & 8405 & $49,6 \%$ \\
\hline Asturias & 77120 & $34,1 \%$ & 19170 & $49,3 \%$ \\
\hline Cantabria & 35375 & $29,6 \%$ & 9430 & $48,2 \%$ \\
\hline Canarias & 93580 & $23,8 \%$ & 8975 & $47,3 \%$ \\
\hline C. Valenciana & 278590 & $31,6 \%$ & 30440 & $45,4 \%$ \\
\hline Castilla-La Mancha & 108665 & $29,4 \%$ & 34570 & $42,6 \%$ \\
\hline Murcia & 74710 & $27,3 \%$ & 11340 & $42,3 \%$ \\
\hline País Vasco & 191025 & $39,1 \%$ & 41700 & $41,2 \%$ \\
\hline Extremadura & 68470 & $29,0 \%$ & 20590 & $39,3 \%$ \\
\hline Galicia & 164845 & $28,9 \%$ & 25260 & $39,1 \%$ \\
\hline Andalucía & 474145 & $27,1 \%$ & 55885 & $37,3 \%$ \\
\hline Baleares & 48630 & $29,3 \%$ & 6245 & $36,2 \%$ \\
\hline Madrid & 468415 & $40,0 \%$ & 67760 & $34,0 \%$ \\
\hline Cataluña & 469880 & $33,7 \%$ & 45180 & $31,7 \%$ \\
\hline Total nacional & 2890825 & $32,2 \%$ & 477960 & $40,3 \%$ \\
\hline
\end{tabular}

Fuente: elaboración propia a partir del Censo de 2011 (INE, 2011) 
El 40,3\% de los jóvenes que residían en una C. A. distinta a la de nacimiento tenían estudios de tercer grado. Castilla y León, a pesar de no ser la autonomía con la proporción más elevada de individuos autóctonos con estudios universitarios, presenta el nivel de instrucción más alto de todo el conjunto nacional entre su colectivo emigrado, 52,1\% de titulados superiores. Le siguen Aragón, La Rioja y, en menor medida, Asturias. También registran un nivel elevado de cualificación entre sus jóvenes emigrados otras regiones de tendencia emigratoria y con un perfil educativo alto. Todas las CC. AA. españolas tienen un nivel de cualificación superior entre su población emigrada respecto al total de nativos, excepto Madrid (34 \%) y Cataluña (31,7\%). El País Vasco registra una cifra similar en ambos casos, aunque se sitúa ligeramente por encima entre los individuos que residen fuera.

Hay una serie de CC. AA. con una tendencia marcadamente expulsora y una población joven altamente instruida, entre las que destaca Castilla y León como región exportadora de talento, seguida de Aragón, La Rioja y Asturias. Cantabria, Castilla-La Mancha y Extremadura también tienen una elevada proporción de emigrados y de emigrados con estudios de tercer grado, pero el nivel educativo de su población autóctona no es tan alto. Otras regiones emigratorias, aunque en menor medida que las citadas, con un nivel educativo elevado son País Vasco y Navarra; en este caso es menos relevante la salida de personas con estudios de tercer grado, pese a que el stock de población total emigrada es significativo, sobre todo en el caso de la primera - parece ser que trata de retener su propio talento, pero con ciertas dificultades-. En cuanto a las regiones que tienen un stock de emigrados universitarios inferior a la media, podemos destacar algunas CC. AA. con un nivel de instrucción bajo, Andalucía, Murcia, Canarias, incluso Galicia. Una proporción más baja de universitarios se traduce en una menor competencia por el empleo cualificado en origen y, por consiguiente, también de la necesidad de emigrar. Cataluña y Madrid son las comunidades autónomas menos emigratorias y presentan niveles altos de cualificación entre su población autóctona. En ambos casos es mayor la proporción de emigrados sin estudios de tercer grado, y el colectivo que reside fuera de la región tiene un nivel educativo inferior respecto al total de la población autóctona. Las Islas Baleares y la Comunidad Valenciana poseen un perfil educativo intermedio y proporciones emigratorias reducidas.

\section{Un balance marcadamente deficitario de población con estudios universitarios. ¿Dónde están los cerebros emigrados?}

En este epígrafe, a partir del stock del censo, nos centraremos en el balance de población joven entre Castilla y León y el resto de CC.AA. españolas - castellano y leoneses que residían en otras regiones e individuos de otras partes de España que vivían en Castilla y León-. El saldo entre ambos colectivos es marcadamente deficitario para la comunidad autónoma (Figura 1), -58 365 efectivos (126 100 emigrados y 67735 inmigrados). Por nivel educativo, las mayores pérdidas se 
dan entre la población con estudios universitarios. El stock del colectivo universitario castellano y leonés emigrado ascendía a 65 985, mientras que los inmigrados de otras partes de España con estudios de tercer grado tan solo sumaban 23 430, con un balance de -42 555 jóvenes talentosos, el 72,9\% del saldo negativo total. No solo se trata de la C. A. más emigratoria del conjunto nacional y la que más talento exporta, sino que la población que entra, bastante menor, tiene un nivel educativo inferior respecto a la que sale: los españoles de otras autonomías que viven en Castilla y León poseen una cualificación limitada, mientras que los castellanos y leoneses que han salido de la región son individuos con un perfil educativo elevado.

Figura 1. Castellanos y leoneses entre 25 y 39 años que residían en otras regiones españolas, personas nacidas en otras CC. AA. que vivían en Castilla y León y balance entre ambos colectivos, por nivel educativo, 2011

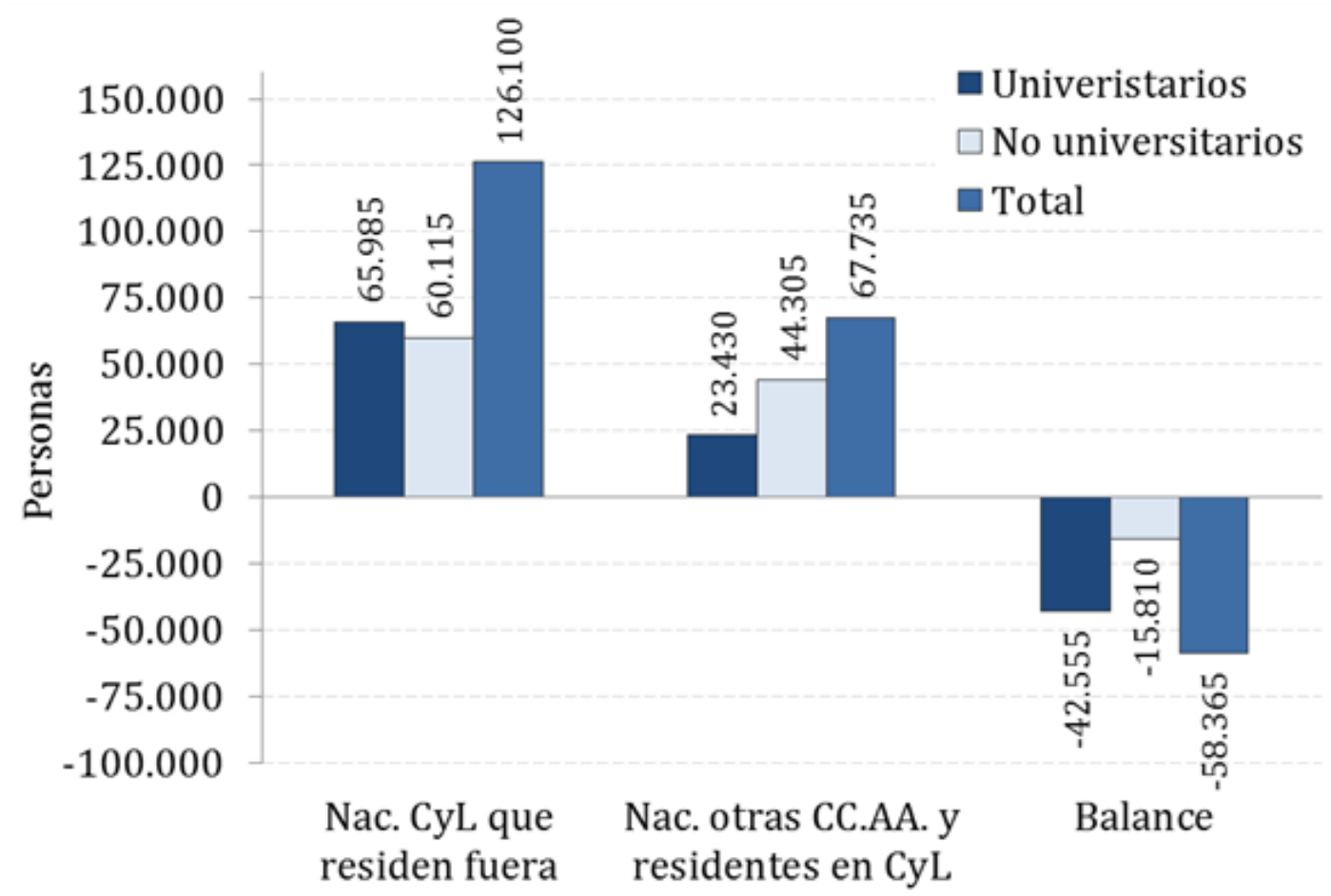

Fuente: elaboración propia a partir del Censo de 2011 (INE, 2011)

Por comunidades autónomas, los mayores intercambios migratorios de jóvenes se han efectuado con Madrid, tanto los flujos de salida como los de entrada (Figura 2). Los primeros, obviamente, son mucho más cuantiosos y están compuestos por una mayor proporción de jóvenes con estudios superiores: de los 51605 castellanos y leoneses residentes en Madrid, cerca del 65 \% tenían estudios universitarios; y de los 18070 madrileños que vivían en Castilla y León, tan solo un 38 \%. Cataluña, la segunda región con más presencia de emigrados, acogía a 10100 individuos (47\% con estudios superiores) y tenía 6780 inmigrados (el 34 \% estaba en posesión de un título 
universitario). El balance total fue de -33 535 jóvenes con Madrid (-26 570 con estudios de tercer grado) y -3320 con Cataluña (-2375 personas con título universitario).

En la Comunidad Valenciana y Andalucía hay una presencia de castellanos y leoneses cercana a la de Cataluña, pero la afluencia de personas nativas de estas regiones hacia Castilla y León ha sido bastante escasa, generando un balance negativo más marcado; aunque, de manera proporcional, hay una presencia menor de universitarios en estos intercambios. Entre los destinos secundarios también destacan algunas CC. AA. colindantes, Asturias Galicia y País Vasco. En todas ellas, también en el resto de destinos, hay una mayor proporción de castellanos y leoneses sin estudios universitarios y lo mismo sucede en el caso de los inmigrados, aunque entre los primeros el nivel educativo es superior.

Figura 2. Castellanos y leoneses entre 25 y 39 años que residían en otras regiones españolas y personas nacidas en otras CC. AA. que vivían en Castilla y León, por comunidad autónoma y nivel educativo, 2011

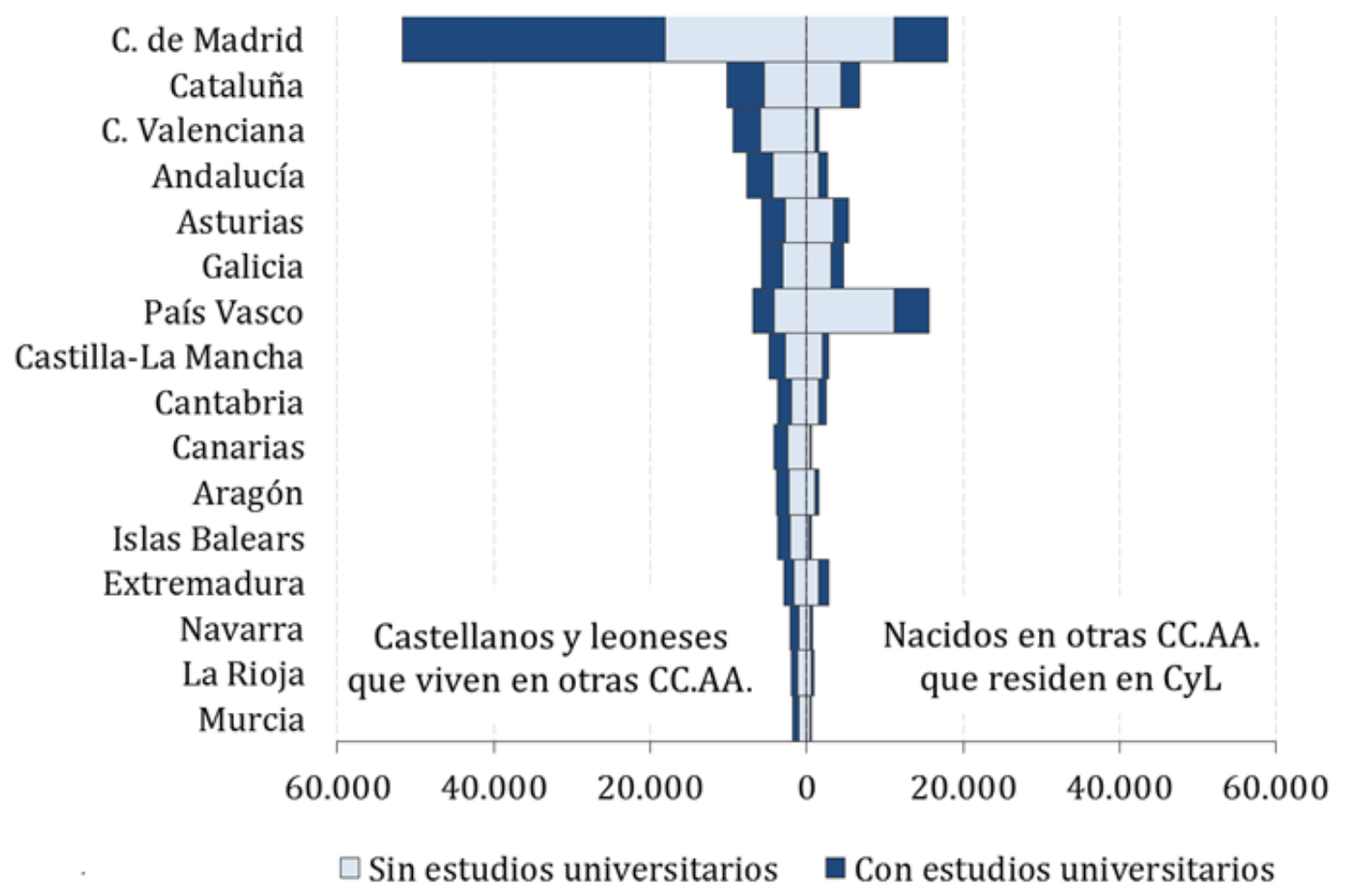

Fuente: elaboración propia a partir del Censo de 2011 (INE, 2011)

Respecto a las CC. AA. que poseen ciertas características análogas, los intercambios son más o menos equilibrados (Asturias, Galicia, Cantabria, Castilla-La Mancha, Extremadura, La Rioja), mientras que con las áreas más dinámicas las corrientes son mayoritariamente de salida (Madrid, Cataluña, Valencia, Baleares). El País Vasco es la única región con la que Castilla y León tiene un balance positivo, pero el $80 \%$ son individuos sin estudios superiores. La elevada presencia de 
vascos en este rango etario se debe a los retornos efectuados por sus progenitores desde mediados de los años 70 (muchos son hijos de castellanos y leoneses nacidos en el País Vasco). También tiene cierta relación con la tenencia de segundas residencias en Castilla y León y los falsos empadronamientos, principalmente al norte de la provincia de Burgos (también de madrileños en el sur de Ávila y Segovia); aunque estas personas no se encuentran en una etapa propicia del ciclo de vida residencial para tal fin (sí sus progenitores en el caso de los individuos más jóvenes).

En la Figura 3 se representa el volumen de jóvenes castellanos y leoneses emigrados por nivel educativo, pero esta vez por provincia de destino. Nuevamente, resalta el principal polo de atracción, la Comunidad de Madrid, donde se encontraban en 2011 el 40,8 \% de los emigrados (un 63,8\% con estudios de tercer grado) y el 50,6\% de los emigrados universitarios. Es destacable señalar que esta comunidad tiene más jóvenes titulados castellanos y leoneses, 33 487, que cada una de las provincias de la propia región, a excepción de Valladolid, 33 913. La segunda provincia receptora es Barcelona, con un 5,7\% y el 5,7\% de los universitarios. Es la provincia catalana que aglutina el grueso de la emigración procedente de Castilla y León, y el resto apenas tienen representatividad. Otras provincias pujantes dentro de determinadas regiones, como es lógico, también aumentan de peso (Zaragoza, Vizcaya, Valencia); mientras que las menos productivas disminuyen (Girona, Tarragona, Lérida, Castellón, Huesca, Teruel, Lugo...). Las dos provincias más dinámicas, cuyas capitales funcionan como centros tecnológicos y financieros, son los principales destinos, sobre todo del talento. El resto de áreas receptoras responden a lógicas territoriales distintas: cercanía, cierto dinamismo... La teoría de las ciudades globales y la atracción de talento parece cumplirse en el caso de la emigración castellana y leonesa; aunque también entran en juego otros factores, como la proximidad, que generan, junto a otros desencadenantes, una serie de fuerzas de atracción que, añadidas a los factores de empuje, configuran la dinámica emigratoria y la dirección de los flujos.

Figura 3. Castellanos y leoneses entre 25 y 39 años residentes en otras provincias españolas, por nivel educativo (2011) 


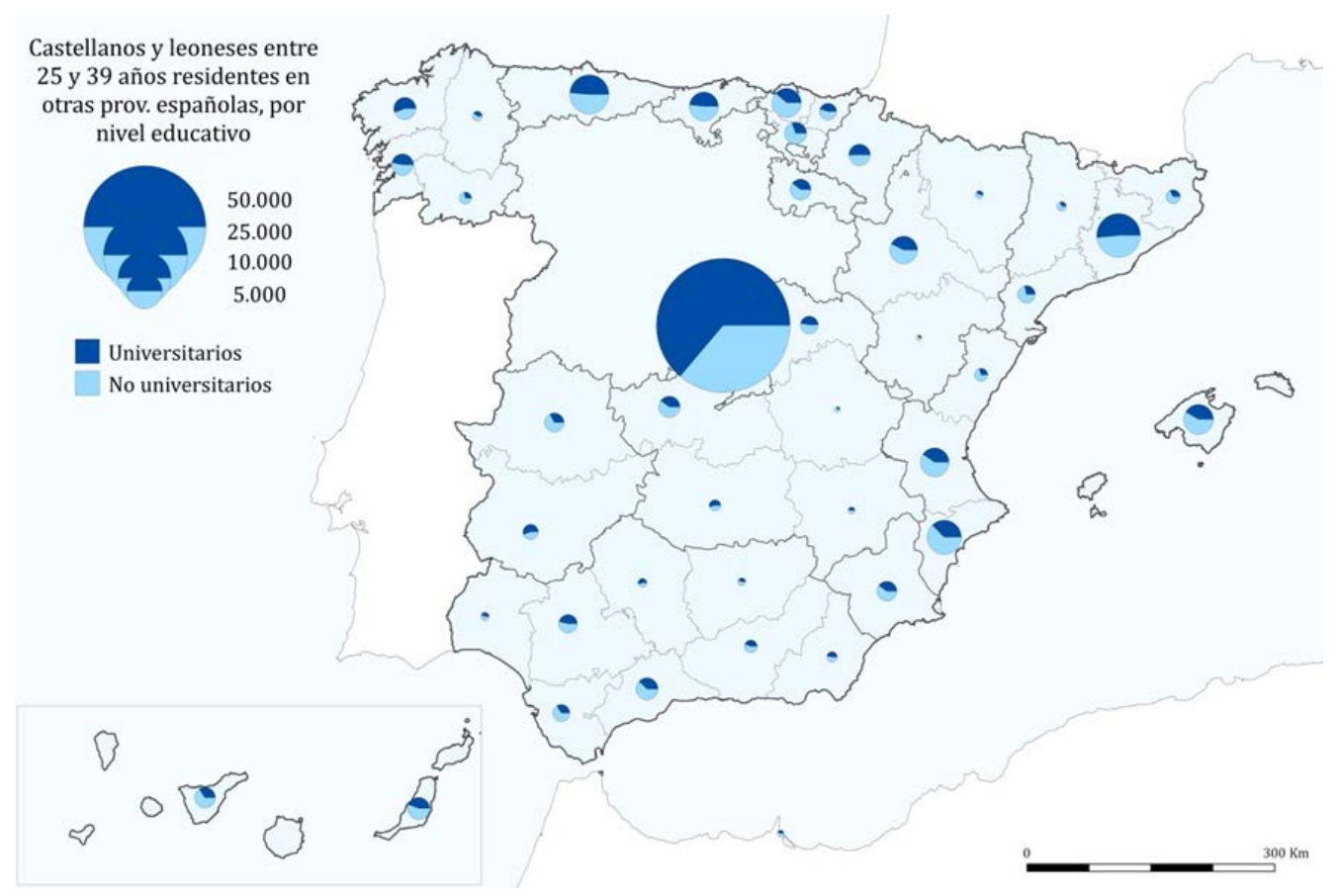

Fuente: elaboración propia a partir del Censo de 2011 (INE, 2011)

\section{Sobrecualificación en origen}

A continuación, se analiza el perfil profesional de los autóctonos castellanos y leoneses de 25 a 39 años con estudios universitarios, comparando la estructura ocupacional de las personas residentes en la región y de la población emigrada. La finalidad es cuantificar el grado de sobrecualificación que existe en Castilla y León entre los individuos con estudios de tercer grado e identificar si los emigrados gozan de una mejor situación laboral. De esta manera, se podría argumentar que la falta de empleos acordes al nivel de instrucción en origen es un claro factor de expulsión, y una mejor oferta en destino un factor de atracción.

Las dos primeras categorías, "directivos y gerentes" y "técnicos y profesionales científicos e intelectuales", englobarían los empleos acordes a una formación superior. El 48,7\% de los titulados universitarios residentes en Castilla y León trabajaban en el agregado de ambas categorías profesionales, y en el colectivo emigrado el porcentaje ascendía hasta el 59,1 \% (Figura 4). En la categoría "técnicos y profesionales de apoyo", cuyos puestos de trabajo, generalmente, requieren una formación profesional superior (FP2), se empleaban el 13,7\% de los residentes autóctonos y el $14,6 \%$ de los emigrados. "Empleados contables y administrativos", "operarios instaladores de maquinaria y montadores" y "trabajadores cualificados de la industria, la construcción y el sector primario", ocupaciones de formación profesional media (FP1), suponían el 20,3, 1,4 y 2,9\% del empleo regional entre los jóvenes autóctonos con estudios universitarios, por este orden; frente al $15,4,1,4$ y $2,9 \%$ en el caso de los castellanos y leoneses emigrados. "Servicios personales" y "ocupaciones elementales", en principio, no requieren cualificación alguna y empleaban al 10,4 y 
2,6 \% de los universitarios que se había quedado en la región, y al 6,8 y 2 \% de los emigrados, respectivamente.

Es evidente que existe un grado importante de sobrecualificación y desperdicio de talento de los jóvenes españoles con estudios superiores. En el caso de las personas autóctonas de Castilla y León, se da entre los residentes en la región, pero también en el colectivo emigrado; aunque es mucho más notable en el caso de los individuos que no se han marchado a otras comunidades autónomas. El porcentaje de universitarios autóctonos sobrecualificado, con una edad comprendida entre 25 y 39 años y que vivían en Castilla y León ascendían al 51,3\%, frente al 40,9% de los que abandonaron la región. Si tenemos en cuenta también la categoría "técnicos y profesionales de apoyo", que en teoría debería englobar a personas con estudios de FP2, los porcentajes a considerar se reducirían hasta el 37,6 \% entre los residentes y 25,5\% en el caso del colectivo emigrado. La presencia de emigrados en estas tres categorías era ampliamente superior respecto a la de residentes, principalmente en las dos primeras. En las categorías profesionales que requieren una formación profesional media había un mayor porcentaje de residentes con estudios superiores, también en las ocupaciones elementales y los servicios personales de baja cualificación.

Figura 4. Perfil laboral de los castellanos y leoneses entre 25 y 39 años con estudios universitarios, residentes en la región y emigrados (2011)

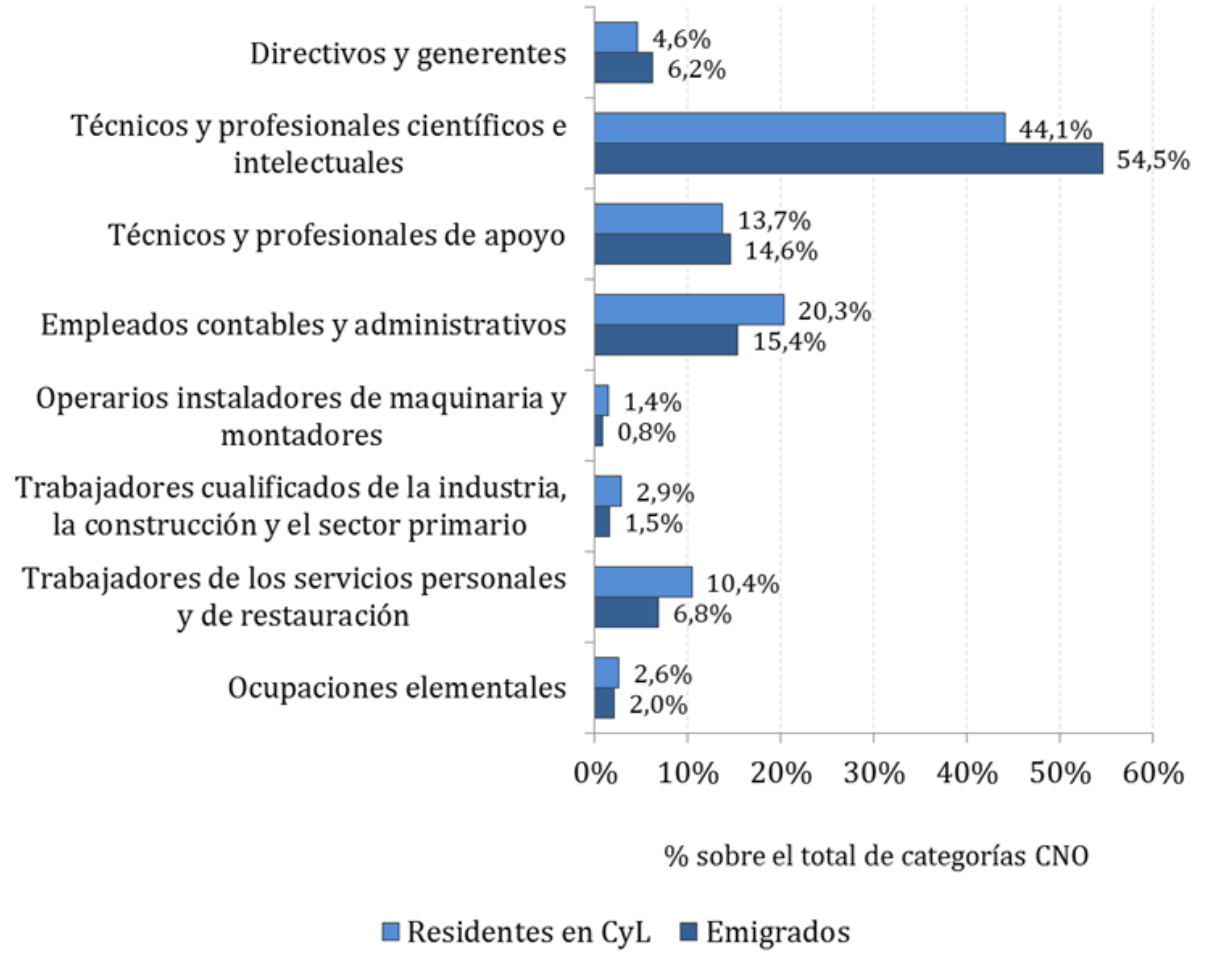

Fuente: elaboración propia a partir del Censo de 2011 (INE, 2011) 


\section{La educación y el perfil ocupacional como principales factores explicativos de la emigración interregional}

Inicialmente, se ha realizado un modelo univariable para cada uno de los factores explicativos referidos en la metodología. Las variables más relevantes han sido el perfil ocupacional del individuo $(7,7 \%)$ y el nivel de instrucción (5,1\%). La provincia de nacimiento explicaba el 1,6 \% de la varianza. La edad, la situación profesional, el ámbito territorial de nacimiento y el sexo han reflejado un $\mathrm{R}^{2}$ más bajo: 0,008, 0,008, 0,003 y 0,002. Seguidamente, se ha realizado un modelo multivariable (Tabla 3), que explica el 11,4 \% de la emigración. Algunas variables pierden poder explicativo, pues interaccionan con otros factores introducidos; como es el caso del sexo, que se torna de una mayor emigración femenina, un $21 \%$ superior respecto a los varones, hacia una menor predisposición de las féminas a efectuar movimiento interregionales - un 4 \% inferior-al controlar por otras variables, principalmente introduciendo el nivel educativo.

En los grupos de edad 30-34 y 35-39 hay una mayor probabilidad de ser un emigrado, 30,3 y $58,2 \%$ superior respecto al grupo 25-29. En realidad, la mayor intensidad emigratoria se da entre 25 y 29 años, pero en este caso estamos trabajando con un stock migratorio acumulado y a medida que se avanza en edad se está expuesto al riesgo de emigrar durante un periodo de tiempo más prolongado. La educación también incide de forma directamente proporcional en la emigración: los individuos con estudios universitarios presentan un Odds ratio de 1,71 respecto a las personas con EGB-ESO o FP1, mientras que la categoría bachillerato-FP2 poseen un OR de 1,22. Los coeficientes se reducen considerablemente respecto al modelo univariable, pues interaccionan con otros factores, entre los que destaca el perfil ocupacional.

En cuanto a la provincia de nacimiento, estableciendo Ávila como referencia, todas las categorías presentan una menor propensión emigratoria, con los siguientes coeficientes: Segovia $(0,79)$, Zamora $(0,71)$, León $(0,71)$, Salamanca $(0,63)$, Burgos $(0,61)$ y Valladolid $(0,41)$. Soria tiene un $\operatorname{Exp}(B)$ cercano a la unidad, pero no es estadísticamente significativo. El ámbito territorial de nacimiento, antes de introducir otras variables y estableciendo <2000 habitantes como grupo de referencia, presenta coeficientes más altos y estadísticamente significativos en las capitales de provincia y otras ciudades de la región ${ }^{1}$, y más bajos en los municipios entre 2000 y 10000 individuos. En el modelo multivariable los coeficientes experimentan una variación sustancial: el $\operatorname{Exp}(B)$ de las capitales desciende hasta 0,97 y la categoría no capitales >10 000 habitantes deja de ser estadísticamente significativa; los municipios de 2001 a 5000 y de 5001 a 10000 descienden medio punto los valores de sus $O R$, sitiándose ambas categorías en 0,71.

1 Los datos referentes al ámbito territorial de nacimiento han de ser tomados con cautela: se trata de una variable autodeclarada y se estima, como se ha señalado en el apartado de fuentes y método, que los municipios de mayor tamaño están sobrerrepresentados en el Censo. 
Los autóctonos con un perfil profesional cualificado tienen una mayor probabilidad de abandonar la región respecto a los trabajadores de los servicios personales: directivos y gerentes $(1,67)$, técnicos y profesionales científicos e intelectuales $(1,84)$, profesionales y técnicos de apoyo $(1,52)$ y trabajadores contables y administrativos $(1,12)$-los Odds ratio son superiores antes de controla por el nivel de instrucción-. Los montadores de maquinaria, los trabajadores industriales, de construcción y agrícolas tienen una probabilidad de emigrar un $35 \%$ menor y los empleados en ocupaciones elementales un -25\%. La situación profesional también influye en la emigración: la probabilidad de que un trabajador por cuenta propia emigre es un 38 \% más baja respecto a un individuo empleado por cuenta ajena, lo que evidencia una mayor capacidad de la región para fijar población emprendedora.

Tabla 3. Modelo multivariable para la emigración en Castilla y León (2011).

\section{Odds ratio de la regresión logística}

\begin{tabular}{|c|c|c|}
\hline Variables explicativas & $\operatorname{Exp}(B)$ & Sig. \\
\hline \multicolumn{3}{|l|}{ Sexo } \\
\hline Hombre & - & \\
\hline Mujer & 0,956 & $* * *$ \\
\hline \multicolumn{3}{|l|}{ Edad } \\
\hline $25-29$ & - & \\
\hline $30-34$ & 1,303 & $\star * *$ \\
\hline $35-39$ & 1,582 & $* \star *$ \\
\hline \multicolumn{3}{|l|}{ Educación } \\
\hline Primario o < & 1,033 & n.s. \\
\hline EGB-ESO-FP1 & - & \\
\hline Bachillerato-FP2 & 1,171 & $\star * *$ \\
\hline Universidad & 1,709 & $\star * *$ \\
\hline \multicolumn{3}{|l|}{ Provincia de nacimiento } \\
\hline Ávila & - & \\
\hline Burgos & 0,609 & $\star \star *$ \\
\hline Palencia & 0,708 & $\star \star \star$ \\
\hline León & 0,636 & $\star \star *$ \\
\hline Salamanca & 0,798 & $* * *$ \\
\hline Segovia & 0,738 & $\star * *$ \\
\hline Soria & 1,006 & n.s. \\
\hline Valladolid & 0,409 & $\star \star *$ \\
\hline Zamora & 0,715 & $\star * *$ \\
\hline
\end{tabular}

Tabla 3. Continuación 


\begin{tabular}{|c|c|c|}
\hline Variables explicativas & $\operatorname{Exp}(B)$ & Sig. \\
\hline \multicolumn{3}{|l|}{ Ámbito territorial de nacimiento } \\
\hline$<2.000$ hab. & - & \\
\hline 2001.-5.000 hab. & 0,709 & $\star * *$ \\
\hline 5.001-10.000 hab. & 0,709 & $* * *$ \\
\hline No capitales > 10.000 hab. & 1,026 & n.s. \\
\hline Capitales de provincia & 0,972 & $\star \star$ \\
\hline \multicolumn{3}{|l|}{ Ocupación } \\
\hline Servicios personales & - & \\
\hline Ocupaciones elementales & 0,775 & $\star \star \star$ \\
\hline Trabajadores cualificados ind. const. y sec. prim. & 0,645 & $\star \star \star$ \\
\hline Montadores de maquinaria & 0,648 & $\star \star \star *$ \\
\hline Contables y administrativos & 1,180 & $\star * *$ \\
\hline Profesionales y técnicos de apoyo & 1,520 & $\star * *$ \\
\hline Técnicos y profesionales científicos e intelectuales & 1,842 & $\star \star \star *$ \\
\hline Directivos y gerentes & 1,668 & $\star \star \star *$ \\
\hline \multicolumn{3}{|l|}{ Situación profesional } \\
\hline Trabajador por cuenta ajena & - & \\
\hline Empresarios y autónomos & 0,618 & $\star \star *$ \\
\hline Otras situaciones & 1,101 & $\star$ \\
\hline Constante & 0,296 & $\star \star *$ \\
\hline Chi Cuadrado & \multicolumn{2}{|c|}{34930,9} \\
\hline-2 log de la verosimilitud & \multicolumn{2}{|c|}{457936,5} \\
\hline R cuadrado de Cox y Snell & \multicolumn{2}{|c|}{0,077} \\
\hline R cuadrado de Nagelkerke & \multicolumn{2}{|c|}{0,114} \\
\hline
\end{tabular}

Valor de significación: ${ }^{* *}<0,001 ; * *<0,01 ; *<0,05 ;$ n.s. $>0,05$.

Fuente: elaboración propia a partir del Censo de 2011 (INE, 2011)

Se puede concluir que las personas muy formadas, con un perfil profesional cualificado y que trabajan por cuenta ajena son los individuos más propensos a abandonar la región. Los emprendedores, según el modelo, emigran menos. Abrir un negocio en Castilla y León tiene una serie de ventajas comparativas respecto a otras regiones de mayor renta per cápita, que podrían estar relacionadas principalmente con una menor inversión y el apoyo de las instituciones locales -viveros de empresas, subvenciones para jóvenes emprendedores y para la creación de actividades en el medio rural-. El sexo, al controlar por las variables nivel educativo y ocupación, se torna desde una mayor emigración femenina hacia una propensión migratoria superior entre los varones; por lo tanto, la movilidad diferencial de las mujeres no deriva del género, sino de un nivel de instrucción superior $y$, por consiguiente, de una mayor capacidad para conseguir mejores empleos.

La intensidad emigratoria en las distintas provincias manifiesta una estrecha relación con el mayor o menor dinamismo económico en cada una de ellas. Los individuos nacidos en territorios con un tejido productivo más potente, como Valladolid, tienen una menor probabilidad a marcharse hacia 
otras regiones, y viceversa. Aunque la intensidad emigratoria interregional es mayor en los ámbitos urbanos y los autóctonos del medio rural tienen una mayor presencia en los movimientos de corta distancia, al introducir otras variables vemos que esta tendencia no es tan evidente. El rural profundo destaca como el ámbito territorial más emigratorio, aunque seguido muy de cerca por las ciudades, con una menor predisposición emigratoria de los autóctonos de municipios entre 2001 y 10000 habitantes -los centros comarcales y algunos municipios suburbanos-.

\section{Conclusiones}

Castilla y León es la región que más jóvenes con estudios universitarios exporta hacia el resto de España, con uno de cada tres autóctonos entre 25 y 39 años y en posesión de un título superior viviendo en otras comunidades autónomas, la proporción más alta de todo el conjunto nacional. En cifras absolutas, a pesar del escaso contingente de personas en este rango etario, ocupa la segunda posición, sólo por detrás de Madrid. El colectivo de emigrantes castellanos y leoneses presenta el nivel de instrucción más elevado, pese a no ser la C. A. con la población autóctona más instruida, aunque tiene un perfil educativo por encima de la media.

En los intercambios con otras autonomías, se observa que la población española que llega a Castilla y León, que es más reducida en comparación al stock de las salidas, tiene un nivel educativo inferior al de los castellanos y leoneses que abandonan la región. La mayor parte de estos intercambios se producen con la Comunidad de Madrid, que es el destino principal de los emigrantes procedentes de Castilla y León, sobre todo de los que presentan un nivel de instrucción elevado. Barcelona, muy alejada del poder de atracción de Madrid, es el segundo destino de personas y talento. En el resto de áreas receptoras (Valencia, Baleares, Andalucía), la proporción de individuos con estudios de tercer grado es menor. Los intercambios son más o menos equilibrados con las CC. AA. que tienen características análogas (Asturias, Galicia, Cantabria, Castilla-La Mancha, Extremadura, La Rioja). El País Vasco es la única comunidad con la que Castilla y León tiene balance positivo (hijos de retornados), pero la mayor parte de esta población no tiene estudios universitarios.

Se observa un grado de sobrecualificación elevado entre los castellanos y leoneses residentes en la región, pero también entre la población emigrada. El desajuste entre el nivel formativo y el perfil ocupacional es más notable en el caso de las personas sedentarias, con un $51 \%$ de jóvenes universitarios empleados en categorías profesionales que requieren un perfil educativo inferior, de acuerdo a nuestra propuesta metodológica, frente al $41 \%$ del colectivo emigrado. Por lo tanto, podemos constatar que los emigrados con estudios superiores gozan de una mejor situación laboral respecto a la población sedentaria. El tipo de empleo, un hard factor, es decisivo en la fuga del talento castellano y leonés hacia otras partes de España. Cabrer et al. (2009) establecen una relación directa entre movilidad y estructura del mercado de trabajo e indican que las personas se 
mueven en respuesta a las oportunidades de empleo, y estas, en el caso de la oferta de trabajo cualificado, se localizan en las áreas económicamente más pujantes.

El modelo pone de manifiesto la elevada incidencia del perfil ocupacional en la emigración. Las categorías profesionales que se encuentran en la cúspide de la pirámide socioeconómica, "directivos y gerentes" y "técnicos y profesionales científicos e intelectuales", presentan probabilidades emigratorias más elevadas. Bóver y Velilla (1999) exponen que un trabajador cualificado tiene una mayor predisposición de trasladarse en busca de mejores oportunidades. Las personas con formación universitaria emigran un 70 \% más que los individuos con estudios de ESOEGB-FP1, un resultado que establece una correlación directa entre emigración y nivel educativo, descrita por Recaño (2014) para el conjunto de España. El rural profundo y las ciudades se posicionan como los ámbitos territoriales más emigratorios en los movimientos interregionales. Las provincias con un tejido productivo más potente son menos emigratorias. El hecho de que los Odds ratio sean más elevados en los grupos etarios 30-34 y 35-39, sabiendo que el rango 25-29 es el más móvil y que las migraciones interregionales han aumentado a lo largo del tiempo en que esta población ha estado expuesta al riesgo de moverse (González-Leonardo, 2017; González-Leonardo \& López-Gay, 2019).), evidencia que los retornos son más bien escasos. La teoría migratoria de la transición de la juventud a la edad adulta (Arnett, 2004; King et. al, 2006), que considera la emigración en edades jóvenes como un estadio del ciclo de vida con el consiguiente retorno a la región de origen, no parece tener mucha incidencia en el nuestro caso de estudio. En resumen, podemos caracterizar el perfil del emigrante castellano y leonés como una persona con estudios universitarios, un perfil ocupacional cualificado, que trabaja por cuenta ajena y, generalmente, no retorna.

El perfil de la emigración castellana y leonesa y la magnitud del stock de adultos jóvenes altamente cualificados que residen fuera de la región nos llevan a definir Castilla y León como la fábrica de talento de España. Los datos analizados en el artículo corresponden a 2011, pero consideramos bastante probable que en los últimos años haya aumentado el nivel de instrucción de la población, mientras que la oferta ocupacional, dado el contexto de crisis económica, se haya precarizado aún más. De continuar con un tejido productivo precario y un marcado desajuste entre las características de la oferta de trabajo y el nivel formativo de la población, es previsible que los jóvenes castellanos y leoneses sigan abandonando la comunidad, una dinámica que alimenta los procesos de despoblación, envejecimiento y empobrecimiento por la pérdida de capital humano y de efectivos jóvenes y talentosos. Mientras tanto, las regiones receptoras resultarían beneficiadas, alimentando un proceso de causación acumulativa (Massey, 1990; Myrdal, 1957), que pone de manifiesto la existencia de un modelo core-periphery (Seers et. al, 1979; King, 2015), en el que Madrid actuaría como centro y Castilla y León como una región periférica que suministra flujos de trabajadores altamente cualificados. Las migraciones internas de jóvenes talentosos hacia las ciudades globales, 
que actúan como centros del sistema, también se dan en otros países: hacia el Área Metropolitana de Nueva York en Estados Unidos (Borjas et. al, 1992), Ámsterdam en Países Bajos (Bontje et. al, 2008) o Helsinki en Finlandia (Maczulskij et. al, 2018).

Agradecimientos: Este trabajo se ha realizado en el marco del Programa de Doctorado en Demografía del Centro de Estudios Demográficos y el Departamento de Geografía de la Universidad Autónoma de Barcelona, dentro de los proyectos: "Comportamientos demográficos y estrategias residenciales: apuntes para el desarrollo de nuevas políticas sociales" (CSO201679142-R) del Ministerio de Economía y Competitividad; "Movilidad residencial, selección sociodemográfica y substitución de la población: ¿̇hacia la polarización de las ciudades españolas?" MOVIPOL (CSO2014-60967-JIN) del Ministerio de Economía y Competitividad y del Programa CERCA / Generalitat de Catalunya.

Declaración responsable: Las/os autoras/es declaran que no existe ningún conflicto de interés en relación con la publicación de este artículo. Miguel González-Leonardo, como autor principal, ha liderado el artículo, se ha encargado de elaborar el marco teórico y de la producción y exposición de los resultados. Antonio López-Gay realizó una contribución substancial estableciendo las bases teóricas y metodológicas, realizando una revisión crítica e introduciendo correcciones. Ambos autores trabajaron conjuntamente en las conclusiones y reflexiones finales. 


\section{Bibliografía}

Albornoz, M., Fernández, E., \& Alfaraz, C. (2002). Hacia una nueva estimación de la fuga de cerebros. Redes, 9(18), 63-84.

Arango, J. (1985). Las leyes migratorias de E.G. Ravenstein cien años después. Revista Española de Investigaciones Sociológicas, 32, 7-26. https://doi.org/10.2307/40183172

Arango, J. (2015). España: una experiencia inmigratoria singular. In C. Torres (Coord.), España 2015. Situación social (pp. 268-275). Madrid: CIS.

Arnett, J. (2004). Emerging adulthood: The winding road from late teens through the twenties. New York: Oxford University Press.

Artal, A., Navarro, J. M., \& Requena, F. (2015). Migraciones interiores en España durante la crisis económica. In E. Aja, J. Arango y J. Oliver (Coords.), Anuario de la Inmigración en España 2014. Flujos cambiantes, atonía institucional (pp. 148-168). Barcelona: CIDOB.

Beine, M., Docquier, F., \& Rapoport, H. (2008). Brain drain and human capital formation in developing countries: winners and losers. The Economic Journal, 118, 631652. https://doi.org/10.1111/j.1468-0297.2008.02135.x

Berg, I. (1970). Education and jobs: the great training robbery. Boston: Beacon Press.

Bóver, O., \& Velilla, P. (1999). Migrations in Spain: historical background and current trends. Madrid: Banco de España.

Bontje, M., Pethe, H., Petrasch, F., \& Tuppinger, K. (2009). Amsterdam: an attractive creative knowledge region? The view of transnational migrants. Amsterdam: AMIDSt and University of Amsterdam.

Borjas, G., Bronar, S., \& Trejo, S. (1992). Self-Selection and internal Migration in the United States. Journal of Urban Economics, 32, 159-185. https://doi.org/10.1016/0094-1190(92)90003-4

Brown, J., \& Męczyńsky, M. (2009). Complexcities: Locational Choices of Creative Knowledge Workers. Built Environment, 35(2), 238-252. https://doi.org/10.2148/benv.35.2.238

Brown, M. (2000). Using the Intellectual Diaspora to Reverse the Brain Drain: Some Useful Examples. In The Regional Conference on Brain Drain and Capacity Building in Africa. United Nations Economic Commission for Africa (UNECA). Addis Ababa.

Buch, T., Hamann, S., Niebuhr, A., \& Rossen, A. (2014). What Makes Cities Attractive? The Determinants of Urban Labour Migration in Germany. Urban Studies, 51(9). https://doi.org/10.1177/0042098013499796 
Caballero, P., Delgado, J.M., \& Martínez, L.C. (2012). La evolución demográfica de Castilla y León: una trayectoria que refleja los rasgos y manifiesta las contradicciones del modelo español. In J.M. Delgado (Coord.), Población y poblamiento en Castilla y León (pp. 301-527). Valladolid: Consejo Económico y Social de Castilla y León.

Cabré, A., Moreno, J., \& Pujadas, I. (1985). Cambio migratorio y reconversión territorial en España. Revista Española de Investigaciones Sociológicas, 32, 4365. https://doi.org/10.2307/40183174

Cabrer, B., Serrano, G., \& Simarro, R. (2009). Flujos migratorios y movilidad del capital humano. Investigaciones Regionales, 16, 5-42. Retrieved from http://hdl. handle. net/10017/29595

Cámara, N. (2009). Los movimientos migratorios internos en la España actual. Estudios Geográficos, 70(267), 351-385. https://doi.org/10.3989/estgeogr.0461

Delgado, J.M, \& Martínez, L.C. (2016a). La Huella de la inmigración extranjera en las Comunidades Autónomas de menor crecimiento demográfico. Cuadernos Geográficos, 55(2), 127-15.

Delgado, J.M., \& Martínez, L.C (2016b). La situación de la población en Castilla y León. Informe Anual de 2015, Serie Monográfica. Valladolid: Consejo Económico y Social de Catilla y León.

Del Rey, A., \& Cebrián, M. (2009). Un doble proceso de despoblamiento en la España interior durante el siglo XX: migraciones y pérdida de nacimiento en Castilla y León. In A. Abellán \& D. Godenan (Coords.), Envejecimiento, despoblación y territorio: un análisis sobre la población española (pp. 583-594). León: Universidad de León.

Dolado, J.J., Felgueroso, F., \& Jimeno, J.F. (2000). Youth labour markets in Spain: Education, training, and crowding out. European Economic Review, 44, 943956. https://doi.org/10.1016/S0014-2921(99)00050-1

Domingo, A., \& Sabater, A. (2013). Crisis económica y emigración: la perspectiva demográfica. In E. Aja, J. Arango \& J.O. Alonso (Coords.), Anuario de la Inmigración en España 2012. Inmigración y crisis: entre la continuidad y el cambio (pp. 60-87). Barcelona: CIDOB.

Domingo, A., \& Blanes, A. (2015). Inmigración y emigración en España: estado de la cuestión y perspectivas de futuro. In E. Aja, J. Arango \& J.O. Alonso (Coords.), Anuario de la Inmigración en España 2014. Flujos cambiantes, atonía institucional (pp. 91-122). Barcelona: CIDOB.

Domingo, A., \& Cabré, A. (2015). La demografía del siglo XXI. Evolución reciente y elementos prospectivos. In C. Torres (coord.), España 2015. Situación Social (pp. 63-73). Madrid: CIS. 
Feria, J.M., \& Susino, J. (2006). La dimensión regional y los nuevos referentes espaciales de las migraciones interiores en España. In J.A. Cordón \& J. Leal Maldonado (eds.), Análisis territorial de la demografía española (pp. 319-359). Madrid: Fundación Abril Martorell.

Florida, R. (2002). The Rise of the Creative Class and How it's Transforming Work, Leisure, Community and Everyday Life. New York: Basic Books.

Franch, X. (2009). La dinámica de las migraciones internas en España: una aproximación demoespacial (Doctoral dissertation, Centre d’ Estudis Demogràfics y Departament de Geografía (UAB), Barcelona, Spain).

Freeman, R. (1976). The overeducated American. New York: Academic Press.

Galeano Reguera, J.M. (2016). Asentamiento territorial de la población extranjera en España a inicios del siglo XXI: segregación residencial, concentración territorial y diversidad poblacional. (Doctoral dissertation, Centre d' Estudis Demogràfics \& Departament de Geografía (UAB), Barcelona, Spain).

Galliard, J. (1991). Scientists in the Third World. Lexington: Kentucky University Press.

García Barbancho, A. (1967). Las migraciones interiores en España. Estudio cuantitativo desde 1900. Madrid: Estudios de Desarrollo Económico.

García Barbancho, A., \& Delgado Cabeza, M. (1988). Los movimientos migratorios interregionales en España desde 1960. Papeles de Economía Española, 34, 240-265.

García Coll, A., \& Puyol, R. (1997): Las migraciones interiores en España. In R. Puyol (Ed.), La dinámica de la población en España (pp. 167-216). Madrid: Síntesis.

García Montalvo, J. (2009). La inserción laboral de los universitarios y el fenómeno de la sobrecualificación en España. Papeles de economías española, 119, 172-187.

García Zarza, E. (1983). La emigración en Castilla y León: causas, características y consecuencias. Valladolid: Consejo General de Castilla y León.

Gobernado Arribas, R. (2007). La sobreeducación en España: Estudio descriptivo y revisión crítica del concepto. Papers, 86, 11-33. http://dx.doi.org/10.5565/rev/papers/v86n0.809

González Ferrer, A. (2013). La nueva emigración española. Lo que sabemos y lo que no. Zoom Político, 18.

González Laxe, F., Martín Bermúdez, F., \& Martín Palmero, F. (2013). Diferencias estructurales, emigración interregional y fuga de cerebros: el caso de Galicia. Revista Galega de Economía, 22(2), 9-30. 
González-Leonardo, M. (2017). El nuevo paradigma de la emigración en Castilla y León: la tercera etapa emigratoria (Master's dissertation, Universidad Autónoma de Barcelona).

González-Leonardo, M., \& López-Gay, A. (2019). El nuevo paradigma de las migraciones internas en España: migrantes urbanos, más móviles y cualificados. El caso de Castilla y León. Scripta Nova, 23(609). http://dx.doi.org/10.1344/sn2019.23.21615

Gordon, A. (2007). Teorías sobre movilidad de científicos y políticas públicas: los enfoques del Brain Drain y Brain Gain y su impacto en las políticas públicas. In IV Jornadas de Jóvenes Investigadores. Buenos Aires: Instituto de Investigaciones Gino Germani y Facultad de Ciencias Sociales (Universidad de Buenos Aires).

Hansen, H., \& Niedomysl, T. (2009). Migration of the creative class: evidence from Sweden. Journal of Economic Geography, 9(2), 191-206. https://doi.org/10.1093/jeg/lbn046

Herrera Ceballos, M.J. (2014). Migración cualificada de trabajadores de España al extranjero. In J. Arango, D. Moya \&J.O. Alonso (eds.), Anuario de la Inmigración en España 2013. Inmigración y emigración: mitos y realidades (pp. 90-107). Barcelona: CIDOB.

INE, Instituto Nacional de Estadística (2011). Microdatos del Censo de Población de 2011.

Instituto Valenciano de Investigaciones Económicas (2009). Flexibilidad laboral y características de los jóvenes. Cuadernos de Capital Humano, 106.

Instituto Valenciano de Investigaciones Económicas (2012). Crisis y mercado de trabajo: una perspectiva regional. Cuadernos de Capital Humano, 133.

Junta de Castilla y León (2016, December 6). Castilla y León obtiene los mejores resultados de España en el Informe PISA 2015 y se sitúa en el séptimo puesto del mundo. Retrieved from http://comunicacion.jcyl.es/web/jcyl/Comunicacion/es/Plantilla100Detalle/128428187317 9//1284680016670/Comunicacion

Kennedy, P. (2010). Mobility, Flexible Lifestyles and Cosmopolitanism: EU Postgraduates in Manchester. Journal of Ethnic and Migration Studies, 36(3), 465482. https://doi.org/10.1080/13691830903426838

King, R., Thomson, M., Fielding, T., \& Warnes, T. (2006). Time, generations and gender in international migration and settlement. In R. Penninx, M. Berger \& K. Kraal (Eds.), The dynamics of international migration and settlement in Europe (pp. 233-267). Amsterdam: Amsterdam University Press.

King, R., \& Lulle, A. (2015). Rhythmic island: Latvian migrants in Guernsey and their enfolded patterns of space-time mobility. Population, Space and Place, 21(7), 599611. https://doi.org/10.1002/psp. 1915 
Kirck, A. (2018). Knowledge Workers' in the Baltic Sea Region: Comparative Assessment of Innovative Performance of the Countries in the Macro-Region. Baltic Journal of European Studies, 8-1(24), 176-196. https://doi.org/10.1515/bjes-2018-0010

Lee, E. (1966). A Theory of Migration. Demography, 3(1), 4757. https://doi.org/10.2307/2060063

López de la Hera, D. (2015). Panorama de la migración internacional en España. In C. Torres (Ed.), España 2015. Situación Social (pp. 196-206). Madrid: CIS.

López-Gay, A. (2008). Canvis residencials y moviments migratoris en la renovaciò poblacional de Barcelona. Barcelona: Consell de Treball Econòmic i Social de Catalunya.

López-Gay, A. (2016). El advenimiento de las regiones metropolitanas maduras en España: retos demográficos y socioeconómicos en un nuevo contexto urbano. Panorama Social, 23, 179-196.

Maczulskij, T., Böckerman, P., \& Kosonen, T. (2018). Job Displacement, Inter-Regional Mobility and Long-Term Earnings. Bonn: IZA-Institute of Labor Economics.

Madrigal, M. (2003). Una revisión de los métodos de medición del desajuste educativo: ventajas e inconvenientes. In X Congreso de Economía Pública. Tenerife.

Martin-Brelot, H., Grossetti, M., Eckert, D., Gritsai, O., \& Kovácz, Z. (2010). The Spatial Mobility of the 'Creative Class: A European Perspective. International Journal of Urban and Regional Research, 34(4), 854-870. https://doi.org/10.1111/j.1468-2427.2010.00960.x

Martínez García, J.S. (2013). Sobrecualificación de los titulados universitarios y movilidad social. In Instituto Nacional de Evaluación Educativa (ed.), Programa internacional para la evaluación de las competencias de la población adulta. Madrid: Ministerio de Educación, Cultura y Deporte.

Massey, D. (1990). Social structure, household strategies and the cumulative causation of migration. Population Index, 56, 3-26. https://doi.org/10.2307/3644186

Mendoza, C., \& Ortiz Guitart, A. (2006). Hacer las Américas. Migrantes españoles de alta calificación en la ciudad de México. Documents d'Anàlisi Geogràfica, 47, 93114. https://doi.org/10.5565/rev/dag.503

Meyer, J., \& Brown, M. (1999). Scientific Diasporas. A new Approach to the Brain Drain. Conferencia Mundial de Ciencia. UNESCO-ICSU. Budapest.

Miguélez, E., \& Moreno, R. (2014). What attracts knowledge workers: the role of space and social networks. Journal of Regional Science, 54(1), 33-60. https://doi.org/10.1111/jors.12069

Módenes, J.A. (2006). Una visión demográfica de la movilidad residencial reciente en España. Papers de Demografía, 292. https://doi.org/10.5477/cis/reis.148.103 
Módenes, J.A., \& López-Colas, J. (2014). Cambio demográfico reciente y vivienda en España: ¿hacia un nuevo sistema residencial? Revista Española de Investigaciones Sociológicas, 148, 103 134.

Musterd, S., \& Murie, A. (2010). Making Competitive Cities. Chichester: Wiley-Blackwell.

Myrdal, G. (1999) [1957]. Rich Lands and Poor. In P. Demetrios \& M. Philip (Eds.), The Unsettled Relationship: Labour Migration and Economic Development (pp. 3-26). New York: Greenwood Press.

Oommen, T. K. (1989). India: 'Brain Drain' or the Migration of Talent? International Migration, 27(3), 371-494. https://doi.org/10.1111/j.1468-2435.1989.tb00355.x

Olano, A. (1990). Las migraciones interiores en fase de dispersión. Revista de economía y sociología del trabajo, 8-9, 86-97.

Pascual de Sans, A. (1983). Los movimientos migratorios de retorno, significado y perspectivas. Documents d'Anàlisi Geogràfica, 3, 47-69.

Pethe, H., \& Hafner, S. (2013). Internationalisation and Policies towards Transnational Migration. In S. Musterd \& Z. Kovács, (Eds.), Place-making and Policies for Competitive Cities. Chichester: Wiley-Blackwell.

Pérez Díaz, V. (1971). Emigración y cambio social: procesos migratorios y vida rural en Castilla. Barcelona: Ariel.

Pérez Díaz, V. (1972). Estructura Social del campo y éxodo rural. Estudio de un pueblo de Castilla. Madrid: Tecnos.

Portes, A., \& Walton, J. (1981). Labor, Class and the International System. New York: Academic Press.

Pugliese, E. (1993). Restructuring of the labour market and the role of Third World migrations in Europe. Environment and Planning D: Society and Place, 5, 497614. https://doi.org/10.1068/d110513

Quintini, G. (2011). Over-Qualified or Under-Skilled: A Review of Existing Literature (OECD Social, Employment and Migration Working Papers, 121).

Rapado, J.M. (1985). Migraciones regionales y evolución de la ocupación en España. In A. Espina, L. Fina \& R. Lorente (Eds.), Estudios de economía del trabajo en España I. Oferta y demanda de trabajo (pp. 369-392). Madrid: Ministerio de Trabajo y Seguridad Social.

Recaño, J., \& Cabré, A. (2003). Migraciones interregionales y ciclos económicos en España (1988-2001). Papeles de Geografía, 37, 179-197. 
Recaño, J. (2004a). Las migraciones internas de retorno en España durante la primera mitad de la década de los noventa: implicaciones demográficas y territoriales. Papers de Demografia, 243.

Recaño, J. (2004b). Migraciones internas y distribución espacial de la población española. In J. Leal (ed.), Informe sobre la situación demográfica en España (pp. 187-228). Madrid: Fundación Fernando Abril Martorell.

Recaño, J. (2006). Los intercambios poblacionales entre las regiones españolas. In J.A. Fernández Cordón \& J. Leal Maldonado (Eds.), Análisis territorial de la demografía española (pp. 273-318). Madrid: Fundación Abril Martorell.

Recaño, J. (2014). Factores sociodemográficos y territoriales de las migraciones internas en España: 1971-2011. In XIV Congreso Nacional de Población (pp. 391-405). Sevilla: Asociación de Geógrafos Españoles.

Recaño, J. (2016). La consolidación de las migraciones internas de inmigrantes como factor estructural de la movilidad geográfica de España. Panorama Social, 24, 49-71.

Reher, D. (1990). Town and Country in Pre-industrial Spain, Cuenca, 1550-1870. Cambridge: Cambridge University Press.

Reher, D. \& Requena, M. (2011). ¿España en la encrucijada? Consideraciones sobre el cambio de ciclo migratorio. Revista Internacional de Sociología. La inmigración en España: perspectivas innovadoras. Monográfico, 1, 9-44. https://doi.org/10.3989/ris.2011.iM1.385

Ródenas, C. (1994). Migraciones interregionales en España (1960-1989): cambios y barreras. Revista de Economía Aplicada, 2(4), 5-36. Retrieved from hitp://hdl.handle.net/10045/23095 Rubio Castillo, A.M. (2014). La emigración de los jóvenes españoles en el contexto de la crisis. Análisis de datos de un fenómeno difícil de cuantificar. Metamorfosis, 1, 101-105.

Sánchez-Sellero, M.C, Sánchez-Sellero, P., Cruz-González, M.M., \& Sánchez-Sellero, F.J. (2013). Sobrecualificación en tiempos de crisis. Revista Venezolana de Gerencia, 64, 584-610.

Sassen, S. (1993). La movilidad del trabajo y del capital: un estudio sobre la corriente internacional de la inversión y del trabajo. Madrid: Ministerio de Trabajo y Seguridad Social.

Saxenian, A. (1999). Silicon Valley's new immigrant entrepreneurs. San Francisco: Public Policy Institute of California.

Seers, D. (1979). Introduction. In D. Seers, B. Schaffer \& M.-L. Kiljunen (Eds.), Underdeveloped Europe: Studies in core-periphery relations (pp. 13-31). Hassocks: Harvester Press.

Serracant Melendres, P. (2005). La nueva economía y la sobrecualificación entre los jóvenes catalanes. Principales resultados de un nuevo sistema de indicadores. Cuadernos de relaciones laborales, 24(1), 199-229. 
Silvestre, J. (2002). Las migraciones interiores en España durante los siglos XX y XXI: una revisión bibliográfica. AGER. Revista de Estudios sobre Despoblación y Desarrollo Rural, 2(8), 227-248.

Sleutjes, B., \& Roterman, W. (2014). Urban Regions in the Delta. Stated preferences of international knowledge workers in The Netherlands. Amsterdam: University of Amsterdam.

Vidal, T. (1979). Èxode rural y problemática demoespacial a Catalunya (1860-1970). Estudis d' Història Agrária, 2, 193-204.

Wallerstein, I. (1974). El moderno sistema mundial. La agricultura capitalista y los orígenes de la economía-mundo europea en el siglo XVI. Madrid: Siglo XXI.

Zipf, G. (1946). The P1P2/D Hypothesis: On the Intercity Movement of Persons. American Sociological Review, 11, 677-686. https://doi.org/10.2307/2087063 